\title{
Composição bromatológica de silagens de híbridos de sorgo cultivados em diferentes densidades de plantas ${ }^{1}$
}

\section{Chemical composition of silage sorghum hybrids grown at different densities}

\author{
Poliana Mendes Avelino², José Neuman Miranda Neiva ${ }^{3 *}$, Vera Lúcia de Araujo ${ }^{4}$, Emerson Alexandrino ${ }^{4}$, Marco
} Aurélio Delmondes Bomfim ${ }^{5}$ e João Restle ${ }^{4}$

\begin{abstract}
Resumo - Avaliou-se a composição bromatológica das silagens de dois híbridos de sorgo, AG-2005 (duplo propósito) e VOLUMAX (forrageiro), cultivados nos espaçamentos de 0,50; 0,75 e 1,00 m, resultando nas densidades de 140.000; 186.666 e 280.000 plantas por ha, respectivamente. A silagem do híbrido AG-2005 apresentou matéria seca (MS) superior no espaçamento de $1,00 \mathrm{~m}$ e foi mais elevada ao da silagem de VOLUMAX em todos os espaçamentos. A proteína bruta (PB) elevou-se com a redução dos espaçamentos (6,6; 6,8 e 8\%, respectivamente), com maior valor médio no AG-2005 (7,7 vs 6,5\%). A fibra em detergente neutro (FDN) foi menor no AG-2005 (59,25 vs 62,3\%) e no espaçamento 0,75 m. Para fibra em detergente ácido (FDA) ocorreu diferença entre os dois híbridos no espaçamento 0,5 m, sendo de 33,5 e 39,3\%, respectivamente, para o AG-2005 e VOLUMAX. O EE apresentou diferença significativa $(\mathrm{P}<0,05)$ entre os dois híbridos no espaçamento $0,75 \mathrm{~m}$, sendo maior no AG-2005 (2,05 vs 1,61\%). Conclui-se que o híbrido AG-2005 é mais recomendado para ensilagem, pois a sua silagem apresenta características qualitativas melhores que do VOLUMAX. O espaçamento de 0,5 m é o mais indicado no plantio dos híbridos, pois melhora a composição química das silagens.
\end{abstract}

Palavras-chave - Espaçamento de plantio. Valor nutritivo. Silagem. Sorgo forrageiro. Sorgo duplo propósito.

\begin{abstract}
The objective of the experiment was to evaluate the nutritive value of silages from two sorghum hybrids, AG2005 (double purpose) and VOLUMAX (forage) cultivated with different row spacings $(0.50 \mathrm{~m} ; 0.75 \mathrm{~m}$ and $1.00 \mathrm{~m})$, resulting in 140,000; 186,666 e 280,000 plants per ha, respectively. Dry matter content of AG-2005 silage was higher for 1 $\mathrm{m}$ row spacing, and was higher than for VOLUMAX silage in all row spacings. Crude protein increased as the row spacing was reduced (6.6; 6.8 and 8\%, respectively), with higher average value for AG-2005 (7.7 vs 6.5\%). Neutral detergent fiber was lower for AG-2005 (59.25 vs 62.3\%) and for .75 m spacing. Acid detergent fiber differed between hybrids in $.5 \mathrm{~m}$ row spacing, being 33.5 and 39.3\%, respectively, for AG-2005 and VOLUMAX. Ether extract was significantly different between hybrids in $.5 \mathrm{~m}$ row spacing, being higher for AG-2005 (2.05 vs 1.61\%). The use of AG-2005 is recommended for silage production due to its better qualitative characteristics than the VOLUMAX. The $.5 \mathrm{~m}$ row spacing is recommended for both hybrids, since it improves the chemical composition of the silages.
\end{abstract}

Key words - Row Spacing. Silage. Nutritional value. Double purpose sorghum. Forage sorghum.

\footnotetext{
*Autor para correspondência

${ }^{1}$ Recebido para publicação em 17/09/2009; aprovado em 19/01/2011

Pesquisa financiada pela CAPES e CNPq

${ }^{2}$ Instituto Federal do Tocantins, Campus de Araguatins-TO, Brasil, zootecnista06@gmail.com

${ }^{3}$ Universidade Federal do Tocantins, Guanabara, 181, Setor Urbano, Araguaína-TO, Brasil, 77.809-080, araguaia2007@gmail.com

${ }^{4}$ Universidade Federal do Tocantins-To, Brasil, veraluciaaraujo@yahoo.com, e_alexandrino@yahoo.com.br, jorestle@terra.com.br

${ }^{5}$ Embrapa-caprinos, Sobral-Ce, Brasil, mabomfim@cnpc.embrapa.br
} 


\section{Introdução}

Em produção de animais ruminantes a alimentação é o componente que tem maior participação nos custos de produção. Restle et al. (2007), realizando a apreciação econômica da terminação de novilhos em confinamento, constataram que a alimentação foi o componente mais oneroso $(77,2 \%)$, com o concentrado representando $75,5 \%$ e o volumoso $24,5 \%$ do custo da alimentação. Os autores ainda ponderam que uma alternativa importante para reduzir os custos com alimentação seria o uso de volumosos de qualidade para substituir parte dos nutrientes fornecidos pelo concentrado.

A qualidade do volumoso é dada pelo seu valor nutritivo, representado pela composição bromatológica do alimento, pela digestibilidade de seus constituintes, consumo voluntário e desempenho do animal (MAGALHÃES et al. 2005; PILAR et al., 1994; RESTLE et al., 2003). A qualidade e o valor nutritivo de uma silagem dependem, fundamentalmente, da aptidão da cultivar e manejo de plantio utilizados, do estádio de maturação no momento do corte e da natureza do processo fermentativo.

A cultura do sorgo para ensilagem se destaca, principalmente, pela alta produtividade em condições adversas como deficiência hídrica e baixa fertilidade do solo. Aliado a isto, pesquisas têm demonstrado a alta qualidade da silagem produzida com essa forrageira, sendo possível sua comparação com culturas já amplamente conhecidas e utilizadas nesse processo (NEUMANN et al., 2004a).

Independentemente dos níveis nutricionais da planta de sorgo em relação a outras forrageiras bem como ao manejo adotado na confecção da silagem (NEUMANN et al., 2005; RESTLE et al., 2002), dentro da espécie Sorghum bicolor existe variabilidade muito grande de composição devido aos muitos híbridos existentes e suas aptidões produtivas: grão, forrageiro ou duplo propósito. Portanto, diversos trabalhos vêm sendo desenvolvidos para caracterização do conteúdo nutricional desses diferentes híbridos e suas silagens (ARAÚJO et al. 2007; GOMES et al. 2006; NEUMANN et al. 2004b;). A aptidão do híbrido de sorgo, além de ser determinante no desempenho dos animais (NEUMANN et al., 2001), podem influenciar as características sensoriais e qualitativas importantes da carne de novilhos (VAZ et al., 2005).

Além dos fatores intrínsecos ao híbrido cultivado, aspectos relacionados ao manejo cultural aplicado têm influência direta sobre produção e qualidade dos nutrientes que compõem a planta. Portanto, uso de espaçamentos mais adensados no plantio podem influenciar quantitativa e qualitativamente o aporte nutricional da forragem cultivada, consequentemente afetando a qualidade da silagem produzida.
Menores espaçamentos entre linhas de plantio, em diversas culturas, são correlacionados com maior rendimento, cobertura mais rápida do solo, maior supressão das plantas daninhas, maior absorção de luz solar e menor perda de água por evaporação, além de maior eficiência das plantas na absorção de água e nutrientes.

Para sorgo, a população ideal depende do híbrido, da fertilidade do solo, da disponibilidade hídrica e da época de semeadura. Desse modo, a produtividade tende a se elevar com o aumento da população, até atingir determinado número de plantas por área. No entanto, faz-se necessária a determinação da composição desse ganho em produção. Assim, objetivouse avaliar os aspectos nutricionais de silagens de dois híbridos de sorgo cultivados em diferentes densidades de plantio na região norte do estado do Tocantins.

\section{Material e métodos}

Esta pesquisa foi realizada na Escola de Medicina Veterinária e Zootecnia da Universidade Federal do Tocantins, Araguaína-TO, no período de janeiro a maio de 2007, localizada em $07^{\circ} 12^{\prime} 28^{\prime}$ ' Latitude Sul, e 48'12'26" Longitude Oeste, com clima, de acordo com a classificação de Köppen, AW - Tropical de verão úmido e período de estiagem no inverno, com temperatura máxima $40{ }^{\circ} \mathrm{C}$ e mínima $18{ }^{\circ} \mathrm{C}$, umidade relativa do ar com média anual $76 \%$ e $2.470 \mathrm{~h}$ insolação/ ano (SEAGRO, 2008). As médias de precipitação e temperatura, máximas e mínimas, durante o período experimental estão apresentadas na Tabela 1 .

Avaliaram-se dois híbridos de sorgo, AG-2005 (sorgo duplo propósito, de ciclo fenológico superprecoce, sem tanino no grão) e VOLUMAX (nome comercial do híbrido AGX-213, sorgo forrageiro, de ciclo semiprecoce, sem tanino no grão), produzidos pela empresa Agroceres, cultivados em três espaçamentos $(0,50 ; 0,75$ e $1,00 \mathrm{~m})$ em esquema fatorial $2 \times 3$, em delineamento de blocos ao acaso com quatro repetições.

O solo da área, Neossolo Quartzarênico Órtico (EMBRAPA, 2006), com as características expressas na Tabela 2, foi previamente submetido à calagem e adubação química de acordo com CFSEMG (1999), com base em análise de solo, exigências da cultura e densidade de plantas. Apresentada na Tabela 2, utilizando-se 2 t/ha calcário dolomítico.

A adubação da área foi executada em função da quantidade de plantas por hectare, visando atender individualmente suas necessidades, ou seja, a partir da indicação de adubação utilizada para cultivo de sorgo foi feito o ajuste para determinação da quantidade disponibilizada por planta. 
Tabela 1 - Somas semanais de precipitação $(\mathrm{mm})$ e médias semanais de temperatura máxima e mínima durante o período experimental

\begin{tabular}{ccccc}
\hline \multirow{2}{*}{ Semana } & \multirow{2}{*}{ Período } & Precipitação $(\mathrm{mm})$ & \multicolumn{2}{c}{ Temperatura $\left({ }^{\circ} \mathrm{C}\right)$} \\
\cline { 3 - 5 } & 31/01 a $07 / 02$ & 192,90 & 30,20 & Mínima \\
\hline 1 & 08/02 a 14/02 & 5,80 & 31,50 & 22,93 \\
3 & $15 / 02$ a 21/02 & 167,60 & 28,84 & 22,44 \\
4 & 22/02 a 28/02 & 128,90 & 30,66 & 22,13 \\
5 & 01/03 a 07/03 & 30,60 & 31,96 & 21,40 \\
6 & 08/03 a 14/03 & 7,20 & 29,67 & 22,00 \\
7 & $15 / 03$ a 21/03 & 73,30 & 29,96 & 22,67 \\
8 & 22/03 a 28/03 & 32,50 & 31,70 & 21,41 \\
9 & 29/03 a 04/04 & 0,00 & 33,03 & 21,51 \\
10 & 05/04 a 11/04 & 26,20 & 31,44 & 22,53 \\
11 & 12/04 a 18/04 & 57,10 & 31,07 & 21,77 \\
12 & $19 / 04$ a 25/04 & 49,70 & 31,23 & 22,24 \\
13 & 26/04 a 02/05 & 37,00 & 29,70 & 21,27 \\
14 & $03 / 05$ a 09/05 & 36,80 & 32,49 & 21,34 \\
\hline
\end{tabular}

Fonte: INMET - Estação Agrometereológica de Araguaína - TO

Tabela 2 - Características químicas e físicas do solo da área experimental

\begin{tabular}{|c|c|c|c|c|c|c|c|c|c|c|c|}
\hline $\mathrm{pH}$ & $\mathrm{Ca}+\mathrm{Mg}$ & $\mathrm{Ca}$ & $\mathrm{Al}$ & $\mathrm{H}+\mathrm{Al}$ & $\mathrm{K}$ & $\mathrm{P}$ & M.O. & & Textura & & C.T. \\
\hline \multirow[t]{2}{*}{$\left(\mathrm{CaCl}_{2}\right)$} & & & & & & & & Argila & Silte & Areia & \\
\hline & --------- & ----- & ${ }^{o l} l_{c} \mathrm{dm}$ & 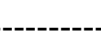 & ------ & $\mathrm{mg} \mathrm{dm^{-3 }}$ & & -------- & 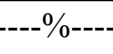 & ------- & \\
\hline 4,2 & 1,4 & 0,6 & 0,25 & 2,5 & 0,08 & 2,3 & 1,4 & 8,0 & 6,0 & 86,0 & Areia \\
\hline
\end{tabular}

Fonte: Laboratório de Solos UFT; M.O. (Matéria orgânica), C.T. (Classe textural)

Realizou-se a semeadura em sulcos de $5 \mathrm{~cm}$ de profundidade e a adubação de implantação mais profunda que a semeadura, com a formulação 5-25-15 de NPK. A adubação de cobertura foi realizada aos 25 e 50 dias após o plantio, com $\mathrm{N}$ e $\mathrm{K}_{2} \mathrm{O}$, em doses de $20 \mathrm{~g} \mathrm{~m}^{-1}$ linear da mistura, $50 \%$ uréia $+50 \% \mathrm{KCl}$. resultando em adubações de $600 \mathrm{~kg} \mathrm{ha}^{-1}, 400 \mathrm{~kg} \mathrm{ha}^{-1}$ e $300 \mathrm{~kg} \mathrm{ha}^{-1}$ de 5-25-15, respectivamente, para os espaçamentos $0,50 \mathrm{~m}, 0,75 \mathrm{~m}$ e $1,00 \mathrm{~m}$. O adubo foi distribuído nas parcelas experimentais segundo a quantidade de linhas de plantio. Portanto, mesmo em populações mais elevadas, a quantidade foi ajustada de acordo com a densidade populacional avaliada.

A adubação de cobertura foi realizada em duas etapas, 25 e 50 dias após o plantio, com $\mathrm{N}$ na forma de uréia e $\mathrm{K}_{2} \mathrm{O}$ na forma de $\mathrm{KCl}$, em dose de $20 \mathrm{~g} \mathrm{~m}^{-1}$ linear da mistura, sendo esta adubação também ajustada segundo o número de plantas por hectare, resultando em adubações de $400 \mathrm{~kg} \mathrm{ha}^{-1}$, 266,6 $\mathrm{kg} \mathrm{ha}^{-1}$ e $200 \mathrm{~kg} \mathrm{ha}^{-1} \mathrm{da}$ mistura uréia $+\mathrm{KCl}$ (50\% de cada) para os espaçamentos $0,50 \mathrm{~m}, 0,75 \mathrm{~m}$ e $1,00 \mathrm{~m}$, respectivamente.

Após 21 dias do plantio realizou-se desbaste nas linhas com a finalidade de ajustar a população para 14 plantas por metro linear. As densidades resultantes foram $140.000 ; 186.666$ e 280.000 plantas por hectare, para os espaçamentos 1,$00 ; 0,75$ e $0,50 \mathrm{~m}$, respectivamente.

As fileiras centrais foram consideradas área útil, eliminando-se as linhas externas laterais e $0,50 \mathrm{~m}$ de cada extremidade das linhas da parcela. A colheita foi realizada quando os grãos atingiram o estádio farináceo, sendo o híbrido AG 2005 colhido aos 85 dias e o VOLUMAX aos 95 dias pós-plantio, mediante corte rente ao solo. Quando 
da ensilagem, retirou-se uma sub-amostra que foi préseca em estufa de ventilação forçada por $72 \mathrm{~h}$, a $65^{\circ} \mathrm{C}$, e armazenadas para posteriores análises da composição bromatológica do material in natura. A composição bromatológica dos híbridos de sorgo antes da ensilagem está apresentada na Tabela 3.

A forragem foi triturada em partículas de aproximadamente $1,0 \mathrm{~cm}$ e ensilada nos 24 silos experimentais de $\mathrm{PVC}$, com $10 \mathrm{~cm}$ de diâmetro e $50 \mathrm{~cm}$ de comprimento, vedados com tampa de PVC, dotados de válvulas tipo Bunsen e lacrados com fita crepe. O material foi compactado com soquetes de madeira, na medida em que se formavam camadas de cinco a $10 \mathrm{~cm}$ de espessura, de modo a se obter maior uniformização e densidade de aproximadamente $600 \mathrm{~kg} \mathrm{~m}^{-3}$.

Os 24 silos foram abertos 100 dias após a ensilagem e obteveram-se sub-amostras de $500 \mathrm{~g}$ de cada silo, as quais foram levadas à estufa de ventilação forçada de ar a $65{ }^{\circ} \mathrm{C}$. Após pré-secagem o material foi moído em moinho tipo Wiley, com peneira com crivos de $1 \mathrm{~mm}$, sendo, em seguida, armazenados para posterior determinação dos teores de matéria seca (MS), proteína bruta (PB), fibra em detergente neutro (FDN), fibra em detergente ácido (FDA), Extrato Etéreo (EE) e cinza (CINZ), determinados segundo metodologia descrita por Silva e Queiroz (2002). Os teores de hemicelulose (Hem) foram estimados utilizando a fórmula: Hem $(\% \mathrm{MS})=\mathrm{FDN}(\% \mathrm{MS})$ - FDA (\%MS). Já os teores de matéria orgânica foram obtidos a partir dos teores de cinzas por meio da fórmula: $\mathrm{MO}$ $(\% \mathrm{MS})=100-$ Cinzas $(\% \mathrm{MS})$. Os teores de carboidratos não-fibrosos (CNF) foram obtidos pela fórmula sugerida por Hall (2000), em que: $\mathrm{CNF}=100-(\mathrm{FDN}+\mathrm{PB}+\mathrm{EE}+$ Cinzas). As análises laboratoriais foram realizadas segundo metodologias descritas em Silva e Queiroz (2002).

As análises bromatológicas,foram realizadas no Laboratório de Nutrição Animal do Centro Nacional de Pesquisa de Caprinos (Embrapa Caprinos em Sobral,CE). Os dados obtidos foram submetidos à análise da variância, com comparação das médias pelo teste de Tukey a 5\% de significância, utilizando-se o programa estatístico Sisvar 5.0 (FERREIRA, 2000).

Tabela 3 - Composição bromatológica (\% da matéria seca) da forragem de híbridos de sorgo in natura cultivados em três espaçamentos de plantio

\begin{tabular}{|c|c|c|c|}
\hline \multirow{2}{*}{ Constituintes } & \multicolumn{3}{|c|}{ Espaçamento (m) } \\
\hline & 1,0 & 0,75 & 0,5 \\
\hline \multicolumn{4}{|c|}{ Volumax } \\
\hline Matéria seca & 33,36 & 33,29 & 33,70 \\
\hline Proteina bruta & 5,55 & 5,90 & 5,91 \\
\hline Fibra em detergente neutro & 56,49 & 59,61 & 62,30 \\
\hline Fibra em detergente ácido & 33,17 & 37,80 & 35,45 \\
\hline Hemicelulose & 23,32 & 21,81 & 26,85 \\
\hline Carboidratos não fibrosos & 30,50 & 28,22 & 25,00 \\
\hline Extrato etéreo & 1,64 & 1,38 & 1,89 \\
\hline Matéria orgânica & 94,18 & 95,11 & 95,10 \\
\hline Cinzas & 5,82 & 4,89 & 4,90 \\
\hline \multicolumn{4}{|c|}{ AG2005 } \\
\hline Matéria seca & 44,44 & 39,88 & 41,86 \\
\hline Proteina bruta & 8,00 & 8,00 & 7,58 \\
\hline Fibra em detergente neutro & 63,17 & 60,55 & 62,78 \\
\hline Fibra em detergente ácido & 34,22 & 31,84 & 31,73 \\
\hline Hemicelulose & 28,95 & 28,71 & 31,05 \\
\hline Carboidratos não fibrosos & 23,79 & 26,77 & 24,97 \\
\hline Extrato etéreo & 1,84 & 1,79 & 1,45 \\
\hline Matéria orgânica & 96,80 & 97,11 & 96,78 \\
\hline Cinzas & 3,20 & 2,89 & 3,22 \\
\hline
\end{tabular}




\section{Resultados e discussão}

Houve interação $(P<0,05)$ híbridos $\mathrm{x}$ espaçamentos para percentagem de MS das silagens (TAB. 4). Independentemente dos espaçamentos, o teor de MS foi maior na silagem do híbrido AG-2005 $(\mathrm{P}<0,05)$ que na silagem do hibrido forrageiro VOLUMAX. Não houve efeito $(\mathrm{P}>0,05)$ de espaçamento sobre o teor de MS da silagem do híbrido forrageiro VOLUMAX. O híbrido
AG-2005 apresentou, no espaçamento 1,00 m, maior teor de MS $(\mathrm{P}<0,05)$ em relação aos demais espaçamentos. Neumann et al. (2004b) afirmam que as diferenças no teor de MS entre híbridos de sorgo são justificadas pela idade de florescimento e composição física da planta e pela suculência do colmo. A importância da suculência do colmo no teor de MS da silagem é evidenciado no trabalho de Restle et al. (2002), quando da manipulação da altura de corte do sorgo de duplo propósito AG-2006 para

Tabela 4 - Teores médios de matéria seca (MS), proteína bruta (PB), fibra em detergente neutro (FDN), fibra em detergente ácido (FDA), hemicelulose, carboidratos não fibrosos (CNF) e extrato etéreo (EE) de silagens de híbridos de sorgo em função dos tipos de híbridos e espaçamentos

\begin{tabular}{|c|c|c|c|c|}
\hline \multirow{2}{*}{ Híbrido } & \multicolumn{3}{|c|}{ Espaçamento (m) } & \multirow{2}{*}{ Média } \\
\hline & 1,0 & 0,75 & 0,5 & \\
\hline \multicolumn{5}{|c|}{$\% \mathrm{MS}$} \\
\hline Volumax & $30,36 \mathrm{aB}$ & $30,36 \mathrm{aB}$ & $30,37 \mathrm{aB}$ & 30,36 \\
\hline AG2005 & $40,55 \mathrm{aA}$ & $36,49 \mathrm{bA}$ & $37,16 \mathrm{bA}$ & 38,07 \\
\hline Média & 35,46 & 33,42 & 33,77 & 34,22 \\
\hline \multicolumn{5}{|c|}{ PB (\%MS) } \\
\hline Volumax & 6,0 & 6,2 & 7,5 & $6,5 \mathrm{~B}$ \\
\hline AG2005 & 7,3 & 7,4 & 8,5 & 7,7 A \\
\hline Média & $6,6 \mathrm{~b}$ & $6,8 \mathrm{ab}$ & $8,0 \mathrm{a}$ & 7,1 \\
\hline \multicolumn{5}{|c|}{ FDN (\%MS) } \\
\hline Volumax & 61,75 & 64,74 & 60,40 & $62,30 \mathrm{~A}$ \\
\hline AG2005 & 60,68 & 61,05 & 56,02 & $59,25 \mathrm{~B}$ \\
\hline Média & $61,21 \mathrm{ab}$ & $62,90 \mathrm{a}$ & $58,21 \mathrm{~b}$ & 60,77 \\
\hline \multicolumn{5}{|c|}{ FDA $(\% \mathrm{MS})$} \\
\hline Volumax & $38,08 \mathrm{aA}$ & $39,35 \mathrm{aA}$ & $39,30 \mathrm{aA}$ & 38,91 \\
\hline AG2005 & $35,89 \mathrm{aA}$ & $35,34 \mathrm{aA}$ & $33,50 \mathrm{aB}$ & 34,91 \\
\hline Média & 36,98 & 37,34 & 36,40 & 36,91 \\
\hline \multicolumn{5}{|c|}{ Hemicelulose (\%MS) } \\
\hline Volumax & 23,67 & 25,39 & 21,11 & $23,39 \mathrm{~A}$ \\
\hline AG2005 & 23,89 & 25,72 & 22,44 & $24,02 \mathrm{~A}$ \\
\hline Média & $23,78 \mathrm{a}$ & $25,55 \mathrm{a}$ & $21,77 \mathrm{a}$ & 23,70 \\
\hline \multicolumn{5}{|c|}{ CNF (\%MS) } \\
\hline Volumax & 26,2 & 22,8 & 24,4 & $24,5 \mathrm{~A}$ \\
\hline AG2005 & 25,5 & 25,2 & 29,1 & $26,6 \mathrm{~A}$ \\
\hline Média & $25,8 \mathrm{a}$ & $24,0 \mathrm{a}$ & $26,8 \mathrm{a}$ & 25,5 \\
\hline \multicolumn{5}{|c|}{$\mathrm{EE}(\% \mathrm{MS})$} \\
\hline Volumax & $1,85 \mathrm{aA}$ & $1,61 \mathrm{bB}$ & $1,96 \mathrm{aA}$ & 1,81 \\
\hline AG2005 & $1,89 \mathrm{aA}$ & $2,05 \mathrm{aA}$ & $2,11 \mathrm{aA}$ & 2,02 \\
\hline Média & 1,87 & 1,83 & 2,03 & 1,91 \\
\hline
\end{tabular}

Letras distintas maiúsculas na coluna e minúsculas na linha, dentro de cada variável, diferem entre si pelo teste Tukey a $5 \%$ de probabilidade. CV (MS) $=1,79 \% ; \mathrm{CV}(\mathrm{PB})=13,13 \% ; \mathrm{CV}(\mathrm{FDN})=5,19 \% ; \mathrm{CV}(\mathrm{FDA})=7,17 \% ; \mathrm{CV}(\mathrm{Hcel})=16,93 \% ; \mathrm{CV}(\mathrm{CNF})=13,11 \% ; \mathrm{CV}(\mathrm{EE})=12,30 \%$ 
ensilagem, uma vez que quando se elevou a altura de corte das planta de $14 \mathrm{~cm}$ para $45 \mathrm{~cm}$, a participação do colmo reduziu de 43,4 para 30,8\%, com redução no teor de MS da silagem de 38,47 para 34,38\%. Outro componente físico da planta que tem influência sobre o teor de MS é a panícula. Estudando diferentes híbridos de sorgo forrageiro e duplo propósito, Neumann et al. (2002b) constataram que no AG-2005 a panícula representou 58,4\% da MS da planta enquanto para o VOLUMAX esse valor foi de $24,6 \%$. Além disso, o teor de MS da panícula foi maior no híbrido AG-2005 (55,74\%) e menor no VOLUMAX (45,72\%).

Avaliando a participação dos três componentes das plantas (Lâmina foliar, caule e panícula) dos dois híbridos, AG-2005 e VOLUMAX, que fizeram parte deste estudo, Avelino (2008) constatou que a panícula foi o componente com maior participação no peso seco da planta, apresentando $43,75 \%$ no VOLUMAX e $57,88 \%$ no AG2005. Além disso, o teor de MS da panícula dos híbridos foi de 49,88 e $56,52 \%$, respectivamente, bem superior ao dos outros componentes. Estas constatações justificam, em parte, o maior teor de MS da silagem do AG-2005.

Mello et al. (2004) obtiveram média de 38,12\% de MS para silagem de AG-2005 cultivado sob uma densidade de 150.000 plantas ha $^{-1}$, valor semelhante ao da média geral obtida para o mesmo híbrido no presente trabalho. Quanto à média obtida para a silagem do VOLUMAX, encontra-se aquém da obtida por Souza et al. (2003) que foi de $35 \%$, com densidade de 125.000 plantas ha $^{-1}$.

O teor de MS da forragem, de acordo com McDonald (1981), pode variar entre 30 e $35 \%$ para obtenção de uma silagem de boa qualidade, pois valores inferiores a $30 \%$ possibilitam o crescimento de bactérias do gênero Clostridium que realizam proteólise e promovem fermentações butíricas. Teores de MS na massa ensilada acima de 45\%, segundo Van Soest (1994), prejudicam a compactação da forrageira no silo, predispondo ao aquecimento do material e ao desenvolvimento de fungos. Além da importância da MS na confecção da silagem e nos seus aspectos qualitativos, o teor de MS pode influenciar o consumo de nutrientes pelos animais, principalmente em dietas com elevada proporção de volumoso, e consequentemente o seu desempenho.

Para os valores de $\mathrm{PB}$ não houve interação $(\mathrm{P}>0,05)$ híbridos $\mathrm{x}$ espaçamentos. Para as médias dos híbridos, o sorgo AG-2005 apresentou teor de PB superior ao do VOLUMAX em todos os espaçamentos. Já para os espaçamentos, observa-se que com 0,50 m entrelinhas a silagem das plantas apresentaram teor de $\mathrm{PB}$ superior $(\mathrm{P}<0,05)$ ao obtido com $1 \mathrm{~m}$ e similar ao obtido com $0,75 \mathrm{~m}$.

Os teores de PB da silagem de híbridos de sorgo dependem da associação de diversos fatores como comportamento agronômico do híbrido, estádio de maturação e condições edafoclimáticas da área de cultivo (GAGGIOTTI et al., 1992). Neumann et al. (2002) obtiveram valores médios para $\mathrm{PB}$ de diferentes híbridos, de 1,$96 ; 5,45$ e 7,62\%, no colmo, folhas e panícula, respectivamente. Portanto, o maior conteúdo protéico na silagem do AG-2005, em relação ao VOLUMAX, foi devido ao maior percentual de panícula na composição da planta e melhor relação folha:colmo $(26,98 ; 15,14 \%$ contra $24,77: 31,48 \%$ ) (AVELINO, 2008).

O maior teor de PB no espaçamento de $0,5 \mathrm{~m}$ foi mais evidente no AG-2005 (8,5 vs 7,5\%), justificado principalmente pela maior participação do componente panícula neste tratamento $(66,99 \%)$ em relação aos demais tratamentos (AVELINO, 2008).

A silagem do híbrido VOLUMAX apresentou nível médio de PB de 6,5\%, valor semelhante aos $6,4 \%$ obtido por Souza et al. (2003) trabalhando com densidade populacional de 125.00 plantas ha ${ }^{-1}$ para o mesmo híbrido, e superior aos $4,8 \%$ obtidos por Neumann et al. (2002) e 5,26\%, por Neumann et al. (2004b), em trabalhos que compararam a qualidade das silagens de híbridos forrageiros e duplo propósito, utilizando espaçamentos entrelinhas de 1,00 e $0,90 \mathrm{~m}$, respectivamente.

Os níveis de $\mathrm{PB}$ dos híbridos testados apresentaram-se próximos a 7\%, considerados como valores mínimos para o bom funcionamento ruminal (VAN SOEST, 1994).

A determinação dos teores das frações fibrosas é importante na caracterização do valor nutritivo das forragens. Tanto o teor de fibra em detergente ácido (FDA) quanto o de fibra em detergente neutro (FDN) são negativamente correlacionados com a digestibilidade da MS, e com o seu consumo (RESTLE et al., 2000; VAN SOEST, 1994).

Para os valores de FDN não foi observada interação $(\mathrm{P}>0,05)$ entre híbridos e espaçamentos. Considerando os valores das médias, de maneira independente para híbrido e espaçamento, o sorgo forrageiro VOLUMAX apresentou maior valor, e, considerando o espaçamento, o menor valor no espaçamento de $0,50 \mathrm{~m}$. Neumann et al. (2004b), trabalhando com híbridos de duplo propósito (AGX-217 e AG-2005), verificaram que estes produziram silagem de menores teores de FDN e FDA que os forrageiros (VOLUMAX; AG-2002), portanto, com melhores valores nutricionais. Os autores obtiveram médias de 74,23 e 65,03\% de FDN para VOLUMAX e AG-2005, respectivamente, ao passo que Mello et al. (2004) obtiveram 61,67\% em AG-2005 e Souza et al. (2003) 64,4\% no híbrido VOLUMAX.

Para os teores de FDA, foi observada interação espaçamentos x híbridos. Os teores de FDA não diferiram entre os híbridos nos espaçamentos 1,00 e $0,75 \mathrm{~m}$, porém 
a $0,50 \mathrm{~m}$ o híbrido VOLUMAX foi superior $(\mathrm{P}<0,05)$. Estes resultados são semelhantes aos obtidos por Mello et al. (2004), 35,07\% para AG-2005 e Von Pinho et al. (2006) que encontraram valores de FDA de 35,4\% (VOLUMAX) e 33,1\% (AG 2005).

Quanto aos teores de hemicelulose, não houve interação para híbrido $x$ espaçamento $(P>0,05)$. Neumann et al. (2004b) obtiveram teores médios de hemicelulose de $39,66 \%$ para VOLUMAX e $34,51 \%$ para AG-2005, valores superiores aos 23,39 e 24,02\% nos híbridos de sorgo respectivamente, obtidos no presente trabalho, possivelmente, devido a alguma irregularidade no processo fermentativo em que maior quantidade deste componente foi consumida, resultando em percentuais abaixo do encontrado na literatura.

Os percentuais de carboidratos não fibrosos $(\mathrm{CNF})$ mantiveram-se semelhantes $(\mathrm{P}>0,05)$, independentemente do híbrido e/ou espaçamento testado. Os valores obtidos no trabalho estão dentro dos padrões conseguidos em estudos anteriores. Mello et al. (2004) obtiveram 25,43\% de CNF para silagem de AG-2005.

Foi observada interação $(\mathrm{P}<0,05)$ híbridos $\mathrm{x}$ espaçamentos para os teores de extrato etéreo (EE). O híbrido VOLUMAX apresentou teores semelhantes entre si nos espaçamentos 1,00 e $0,50 \mathrm{~m}$, sendo estes superiores à média obtida no espaçamento $0,75 \mathrm{~m}$. Quando comparados os híbridos, o AG-2005 apresentou-se superior ao VOLUMAX no espaçamento $0,75 \mathrm{~m}$, sendo semelhante nos demais espaçamentos. Os valores encontrados no estudo estão aquém dos obtidos por Mello et al. (2004) que obtiveram 3,39\% de EE para silagem de AG-2005 cultivada em espaçamento entre fileiras de $0,7 \mathrm{~m}$.

\section{Conclusões}

1. O adensamento no espaçamento de plantio melhora o valor nutritivo das silagens, pois eleva o teor de proteína bruta e diminui os teores de fibra em detergente neutro;

2. O híbrido AG-2005 é mais indicado para produção de silagens, pois apresenta melhores características nutricionais.

\section{Agradecimentos}

À Monsanto pela doação das sementes de sorgo e à Embrapa-Caprinos pela realização das análises químicobromatológicas e em especial ao técnico de laboratório Valdécio pela agilização no processamento do material.

\section{Referências}

ARAÚJO, V. L. et al. Qualidade das silagens de três híbridos de sorgo ensilados em cinco diferentes estádios de maturação. Arquivo Brasileiro de Medicina Veterinária e Zootecnia, v. 59, n. 01, p. 168-174, 2007.

AVELINO, P. M. Características produtivas e qualitativas de híbridos de sorgo (sorghum bicolor, l. moench) para produção de silagem, cultivados sob diferentes densidades de plantio. 2008. 56 f. Dissertação (Mestrado em Ciência Animal Tropical) - Universidade Federal do Tocantins, Araguaína.

COMISSÃO DE FERTILIDADE DO SOLO DO ESTADO DE MINAS GERAIS (CFSEMG). Recomendações para o uso de corretivos e fertilizantes em Minas Gerais. 5. ed. Lavras: SBCS, 1999. 359 p.

EMPRESA BRASILEIRA DE PESQUISA AGROPECUÁRIA (EMBRAPA). Sistema brasileiro de classificação de solos. 2. ed. Rio de Janeiro: Embrapa Solos, 2006. 306 p.

FERREIRA, D. F. Análises estatísticas por meio do Sisvar para Windows versão 4.0. In: REUNIÃO ANUAL DA REGIÃO BRASILEIRA DA SOCIEDADE INTERNACIONAL DE BIOMETRIA, 45., 2000, São Carlos. Anais... São Carlos-SP: UFSCar,2001. p. 255-258.

GAGGIOTTI, M. C. et al. Cultivares de sorgo forrageiros para silaje. II. Características fermentativas y nutritivas de los silajes. Revista Argentina Producción Animal, v. 12, n. 02, p. 163-167, 1992.

GOMES, S. O. et al. Comportamento agronômico e composição químico-bromatológico de cultivares de sorgo forrageiro no Estado do Ceará. Revista Ciência Agronômica, v. 37, n. 02 , p. 221-227, 2006.

HALL, M. B. Neutral detergent-soluble carbohydrates. Nutritional relevance and analysis. Florida: University of Florida, 2000. (Bulletin, 339).

MAGALHÃES, R. T. et al. Estimativa da degradabilidade ruminal de quatro genótipos de sorgo (Sorghum bicolor (L.) Moench) utilizando a técnica in situ. Acta Scientiarium. Animal Sciences, v. 27, n. 04, p. 483-490, 2005.

MCDONALD, P. The biochemistry of silage. New York: John Willey \& Sons. 1981. 226 p.

MELLO, R.; NÖRNBERG, J. L.; ROCHA, M. G. Potencial produtivo e qualitativo de híbridos de milho, sorgo e girassol para ensilagem. Revista Brasileira de Agrociência, v. 10, n. 01, p. 87-95, 2004.

NEUMANN, M.; RESTLE, J.; BRONDANI, I. L. Avaliação de silagens de sorgo (Sorghum bicolor, L. Moench) ou milho (Zea mays, L.) na produção do novilho superprecoce. Revista Brasileira deMilho e Sorgo, v. 03, n. 03, p. 438-452, 2004a.

NEUMANN, M. et al. Avaliação da qualidade e do valor nutritivo da silagem de híbridos de sorgo (Sorghum bicolor, L. Moench). Revista Brasileira de Milho e Sorgo, v. 03, n. 01, p. 120-133, 2004b.

NEUMANN, M. et al. Avaliação da Silagem de Diferentes Híbridos de Sorgo (Sorghum bicolor, L. Moench) por meio do 
Desempenho de Novilhos de Corte Confinados. Revista Brasileira de Zootecnia, v. 30, n. 06, p. 2099-2109, 2001.Suplemento.

NEUMANN, M. et al. Avaliação de Diferentes Híbridos de Sorgo (Sorghum bicolor, L. Moench) quanto aos Componentes da Planta e Silagens Produzidas. Revista Brasileira de Zootecnia, v. 31, n. 01, p. 302-312, 2002. Suplemento.

NEUMANN, M. et al. E feito do tamanho da partícula e do tipo de silo sobre o valor nutritivo da silagem de sorgo (Sorghum bicolor, L. Moench). Revista Brasileira de Milho e Sorgo, v. 4, n. 02, p. 224-242, 2005.

PILAR, R. C. et al. Silagens de milho (Zea mays, L.) ou capim elefante (Pennisetum purpureum, Schum.) cv. Napier para alimentação de terneiros de corte confinados. Ciência Rural, v. 24, n. 02, p. 387-392, 1994.

RESTLE, J. et al. Palha de soja (Glicine max) como substituto parcial da silagem de sorgo forrageiro (Sorghum bicolor L. Moench) na alimentaçãode terneiros de corte confinados. Ciência Rural, v. 30, n. 02, p. 319-324, 2000.

RESTLE, J. et al. Manipulação da altura de corte da planta de milho (Zea mays, L.) para ensilagem visando a produção do novilho superprecoce. Revista Brasileira de Zootecnia, v. 31, n. 03, p. 1235-1244, 2002.

RESTLE, J. et al. Avaliação da silagem de capim papuã (Brachiaria plantaginea) por meio do desempenho de bezerros de corte confinados. Ciência Rural, v. 33, n. 04, p. 749-756, 2003.

RESTLE, J. et al. Apreciação econômica da terminação em confinamento de novilhos Red Angus superjovens abatidos com diferentes pesos. Revista Brasileira de Zootecnia, v. 36, n. 04, p. 978-986, 2007.

SECRETARIA DE AGRICULTURA, PECUÁRIA E ABASTECIMENTO DO ESTADO DO TOCANTINS (SEAGRO). O clima no Tocantins. Disponível em: $<$ http://seagro. to.gov.br/conteudo.php?id=21>. Acesso em: 30 jul. 2008.

SILVA, D. J.; QUEIROZ, A. C. Análises de Alimentos: Métodos químicos e biológicos. 2. ed. Viçosa: UFV, 2002. 165 p.

SOUZA, V. G. et al. Valor Nutritivo de Silagens de Sorgo. Revista Brasileira de Zootecnia, v. 32, n. 03, p. 753-759, 2003.

VAN SOEST, P. J. Nutritional ecology of the ruminant. 2. ed. New York: Cornell University Press, 1994. 476 p.

VAZ, F. N. et al. Nível de concentrado, variedade da silagem de sorgo e grupo genético sobre a qualidade da carcaça e da carne de novilhos confinados. Revista Brasileira de Zootecnia, v. 34, n. 01, p. 239-248, 2005.

VON PINHO, R. G. et al. Influência da altura de corte das plantas nas características agronômicas e valor nutritivo das silagens de milho e de diferentes tipos de sorgo. Revista Brasileira de Milho e Sorgo, v. 05, n. 02, p. 266-279, 2006. 